\title{
Chapter 8 \\ Pandemic Communication Without Argumentative Strategy in the Digital Age: A Cautionary Tale and a Call to Arms
}

\section{Fabio Paglieri}

\begin{abstract}
The Covid-19 pandemic has offered some notable examples of how public communication may backfire, in spite of the best intentions of the actors involved, and what role poor argumentative design plays in such failures, in the context of the current digital media ecology. In this chapter, I offer some preliminary considerations on the ongoing struggle to make sense of the new communication technologies in our media reality, analyze a concrete example of argumentative failure in anti-Covid vaccine communication in the European Union, and leverage this case study to issue a call to arms to argumentation scholars: argumentative competence is sorely needed for an effective response to the pandemic, yet argumentation theory will need to join forces with other areas of expertise to realize its societal impact. When it comes to arguments, self-isolation is not a viable strategy to fight Covid-19.
\end{abstract}

Keywords Online debate $\cdot$ Health communication • Argumentative strategies • Virality $\cdot$ Argument technologies

\subsection{Introduction: A Tale of Many Waves}

The mainstream narrative on the role of digital technologies in public discourse has always come in waves, occasionally overlapping each other. Gen Xers like myself, i.e. people born in between the late $60 \mathrm{~s}$ and early $70 \mathrm{~s}$ of the last century, have fond memory of the first wave: it was a time when digital technologies were still a novelty, when sending an email to another part of the globe and getting an answer within, say, $48 \mathrm{~h}$ was a near miracle, when smartphones did not exist and the first cellular phones were rare, cumbersome, and exotic-a time when getting online was perceived as a step towards a brighter future, no question asked. The Internet was hailed as the harbinger of a new age of global democratic engagement and the technological panacea to a variety of societal challenges: economic disparities, information

F. Paglieri $(\bowtie)$

Istituto di Scienze e Tecnologie Della Cognizione, CNR, Roma, Italy

e-mail: fabio.paglieri@istc.cnr.it

S. Oswald et al. (eds.), The Pandemic of Argumentation, Argumentation Library 43, https://doi.org/10.1007/978-3-030-91017-4_8 
access, civic participation, lack of rational discussion, culture-based incomprehension, even nationalism. Prominent heralds of this initial optimism included scholars like Negroponte (1995) and Dertouzos (1997), and there was widespread consensus on the value of the collective intelligence made possible by the Internet, which years later would have been popularized by James Surowiecki's concept of "wisdom of crowds" (2004).

However, around the turn of the century, the narrative started to change: the second wave brought growing skepticism on the impact of digital technologies on democracy and society in general, as argued in the works of Shapiro (1999) and Sunstein (2001), among others. These misgivings continued to multiply over the next decades, often producing valuable insight on the dark side of our digital engagements, as in Sherry Turkle's exploration of the adverse effects of social media on interpersonal relationships (2011), but occasionally resulting in rather superficial misrepresentations of the alleged problems created by new technologies, as in the infamous best-seller The shallows: What the internet is doing to our brains by Nicholas Carr (2020, based on his equally successful 2008 article in The Atlantic, "Is Google making us stupid?"). Over the years, much of the concerns tended to accrue on social media, so much so that the prominent computer scientist Jaron Lanier felt compelled to list Ten arguments for deleting your social media accounts right now (2018).

More recently, such worries started being paired with raising panic about the "new" plague of disinformation. The scare quotes around "new" are mandatory here, considering that disinformation has been around since we evolved the ability to communicate. Nonetheless, in the last decade fake news became the buzzword of choice to scare away youngsters from digital apps, as well as a convenient scapegoat for any communication misstep of private and public institutions. In the meantime, the World Economic Forum dedicated an entire section of its Global Risk 2013 report to "digital wildfires in a hyperconnected world" (Howell, 2013), the Oxford Dictionary was busy declaring "post truth" to be the word of the year 2016, and just one year later Time magazine, in the wake of the election of Donald Trump to the Presidency of the United States, asked on its cover "Is truth dead?" (a self-citation of its iconic 1966 cover, "Is God dead?"). Bold claims were made and widely shared on the impact of social media campaigns in determining important political events, such as the Brexit referendum or the Presidential elections in the US, and monikers like "trolls", "hackers", and "information operations" became more and more frequent in media discourse. The oversimplification of those claims and the imprecision of those monikers did not detract from their popularity, with politicians, academics, and journalists taking turn in publicly admonishing the masses against the dangers of unsupervised access to digital information platforms. In the midst of this frenzy, social media ended up being considered by many as public enemy number one of rational discourse.

And now? How is the ongoing Covid-19 pandemic shaping our public perception of digital technologies and their role in collective reasoning and democratic engagement? Not surprisingly, most media were all too eager to draw an easy analogy between the virus and the spreading of disinformation about it, so that "infodemic" became yet another buzzword in this domain of discourse. This is not necessarily 
problematic, insofar as there are good grounds for the analogy: e.g., virality is indeed a key element in information diffusion, and several epidemiologic concepts, such as replication rate, can be usefully applied to information dynamics. Yet the label may lead to equivocation when used to evoke fear, or to imply that what is being spread by an "infodemic" is necessarily misleading, false, or otherwise defective news. In contrast, recent studies on the circulation of Covid-related content on social media have shown that, while the volume of disinformation distributed on various platforms differs, "information from both reliable and questionable sources do not present different spreading patterns" (Cinelli et al., 2020); in other words, contra popular belief and previous research (e.g., Vosoughi et al., 2018), it is not true that a lie gets halfway around the world before the truth has a chance to get its pants on.

In spite of the dramatic consequences of any misinformation associated with a lethal pandemic (but again, read Thucydides to see how much the same was happening already in the V century B.C., when Athens experienced a severe plague and falsely blamed the Spartans for it), the current trend of research may indicate the beginning of a third wave, in our unresolved struggle to make sense of digital technologies in public discourse: after the initial optimism and the ensuing pessimism, we are entering a more nuanced phase, one best described by the Facebook relationship status "It's complicated!". The complexity and the velocity of the transformations brought about by online platforms is once again being appreciated, this time not to pass hasty, all-encompassing judgments on their overall value, but rather to make a serious study of them, to highlight both pros and cons of our new information ecology (Floridi, 2014), to develop suitable tools to understand it and appropriate policies to improve it - or so we can hope, at least.

This unresolved struggle can be usefully framed as a manifestation of "media logic" (Altheide \& Snow, 1979), to describe the complicated process by which institutions rebuild their communication practices to fit new environments. This line of work has been fruitfully applied to online environments, and in particular to social media platforms (van Dijck \& Poell, 2013). One of the important themes in this work is that our initial experiences with new communication media nearly always involve a mismatch between our legacy communication practices and the demands of the new media. It takes time and creative effort for society to learn how to live in a new communication environment and how to find advantage in what seems at first to be a collapse of common sense. In relation to the profound transformations brought about by digital communication platforms, what we are witnessing (and will probably continue to witness for some time) is an extended period of largely unpredictable inventiveness at the level of communication practices.

The role of argumentation theory in all of that remains to be established, and it constitutes the gist of this volume. Prima facie, there are good reasons to expect rational argumentation to be an essential ingredient in any healthy scenario of technology-mediated public discourse, all the more so in times of global crisis. To put it bluntly, how can we ever hope to support rational discursive interactions and responsible epistemic practices among users of digital technologies, without first understanding what makes those interactions rational and those practices responsible? Unfortunately, in spite of all this potential, so far argumentation scholarship 
has largely failed to make a substantial impact on how public debate is conducted: argument-based analyses of real life discourse are frequent and often enlightening, yet policy-makers do not heed them in their (rare) attempts at improving the quality of citizen participation and democratic engagement, online or otherwise; similarly, argument technologies, including argument mining, are a thriving area of research in AI, yet it is doubtful that they are currently poised to scale up beyond research-driven applications (Paglieri, 2017).

However, the ongoing pandemic is providing numerous examples (often tragic ones, alas!) of how ignoring basic principles of argumentative design may severely impair the effectiveness of public discourse for the management of the current health crisis. More generally, such examples highlight how dealing with complex societal phenomena without curating their argumentative side is a recipe for disaster. In what follows, I will analyze a specific instance of this phenomenon: I will start from a single discursive contribution made by a prominent medical expert, to show how this is indicative of a more general and basic argumentative failure in anti-Covid vaccine communication in Italy, and more generally in the European Union (Sect. 8.2). This will serve to outline some crucial contributions that argumentation theory may offer to the scaffolding of better public discourse on the ongoing pandemic: in fact, Sect. 8.3 is devoted to taking stock of these insights, as well as offering some interim conclusions and clarify the role of social media in these dynamics (as we shall see, they mostly act as amplifiers of whatever message is put out there, regardless of its source).

\subsection{Of Herd Immunity and Rotten Carrots: The Argumentative Debacle of Vaccine Communication in the $\mathbf{E U}$}

In November 2020, a prominent Italian medical expert injected a problematic issue in the debate on anti-Covid vaccines, which was immediately picked up on social media and by traditional news outlets. The occasion was a popular talk show on national television, Dimartedi, aired every Tuesday night on the La7 channel: during the pandemic, one of the frequent guests of the broadcast was Ilaria Capua, Full Professor at the University of Florida and Director of the One Health Center of Excellence for Research and Training. Besides being a member of the EU Parliament for 3 years (2013-2016), Capua is well-known in the medical community for her groundbreaking work on the avian influenza in 1999-2000: in other words, she is a well-reputed scientist and an authoritative voice on issues related to the pandemic.

On November 24, 2020, Capua was asked by the host of the show, Giovanni Floris, to explain how the anti-Covid vaccines under development would work. In answering the question, ${ }^{1}$ Capua introduced to the general public the issue of sterilizing immunity, as follows:

\footnotetext{
${ }^{1}$ The clip of her statement is available here (in Italian): https://www.la7.it/dimartedi/video/comefunzionano-i-vaccini-anti-covid-la-spiegazione-di-ilaria-capua-24-11-2020-352054.
} 
There are very few vaccines that grant sterilizing immunity: that is, that make me completely impermeable to the virus. What happens instead in the real world and in the natural world? If I am vaccinated, I have defenses against the negative effects that the virus would produce in me. Thus, the vaccine shields me from the illness. But does it also prevent infection? If you are asking me: "After vaccination, will I be able to get back to my life as if I was $100 \%$ safe", the answer is "No!". Because the virus, when it comes into contact with a vaccinated person, goes through a first replication cycle, therefore the efficacy of the vaccine means efficacy against the illness. Instead, it is not $100 \%$ effective against infection: however, it does reduce a lot the amount of virus being eliminated. To sum up: if you get the vaccine, then you will not get ill. But can you still get infected and transmit the virus to others, if you stop wearing a facemask? Yes. Thus, it is not the case that, when the vaccine will come, everyone will be free and without a care in the world. It is important to understand that the vaccine, once available, will not be a panacea. It will not mean "Once we used to have a problem, now it is all good": it will just be one of the tools for us to use in the upcoming months.

There is a lot of relevant information in this passage, in spite of some occasional obscurity and infelicity of expression (e.g., it is unclear how reducing the amount of virus being eliminated could make vaccine more effective against infection). It is also clear that what motivates Capua to talk at length about sterilizing immunity is the need to explain that being vaccinated should not be considered as a free pass to do whatever one pleases, since vaccinated people can still get infected and transmit the virus to others. However, once inserted in the general debate on vaccination, Capua's message raises two problematic implications: (i) it makes people skeptical that herd immunity against Covid-19 will ever be attained, since apparently getting vaccinated does not prevent the spread of the virus; (ii) it risks reinforcing a typical anti-vaccination concern, namely, the idea that the vaccine itself makes people contagious for others.

Let us first consider the latter issue. The (mistaken) reasoning behind it goes more or less as follows: "You are telling me that vaccinated people can still get infected and transmit the Covid-19 virus to others, and I know that vaccines work by inoculating small doses of the virus to the patient: therefore, the vaccine shot itself will turn vaccinated people into asymptomatic carriers of the disease, thereby accelerating the spread of the virus". The pitfall of this line of reasoning is in the assumption that the viral carrier used in vaccines is capable of replicating, and therefore contagious. This is not the case in general, and it is certainly not the case with anti-Covid vaccines: those based on mRNA technology, like Pfizer and Moderna, do not even contain viral carriers, but rather use mRNA strings to tell the patient's cells how to produce the immunitary response to the virus; and even those vaccines that contain a viral carrier, like AstraZeneca and Johnson \& Johnson, are carefully designed to ensure that the viral load is incapable of supporting replication-that is, they do not make people contagious.

Unfortunately, all of this is fairly technical, so the message needs to be spelled out in simpler and more impactful terms for the general public. A good attempt at doing that had already been put forward by another Italian medical expert, Roberto Burioni, two years earlier (November 2018), as follows²:

\footnotetext{
${ }^{2}$ Source (in Italian): https://www.medicalfacts.it/2018/11/20/vaccinati-trasmissione-virus/
} 
Most vaccines (hexavalent, antipneumococcal, anti-HPV, antimeningococcus) are made by single components of the virus or the bacterium. To speculate that from single proteins or other molecules may come out something capable of self-replicating is like thinking that the soup cube in your fridge may magically turn into a full-size calf.

Burioni, who is Professor of Microbiology and Virology at the Vita-Salute San Raffaele University of Milan, a science communication star in Italy, and a selfappointed blaster of pseudo-science on his website Medical Facts (https://www.med icalfacts.it/), directly intervened also on Capua's declarations. On November 25, 2020, in response to her TV statement, Burioni wrote on Twitter $^{3}$ :

Some say that (in general) vaccinated people are protected but they can be contagious. THIS IS NOT TRUE. For measles, rubella, mumps or chickenpox - and the list could go on - who is vaccinated cannot be infected and CANNOT transmit the virus. Clearly we don't know anything of what may happen with the various anti-Covid-19 vaccines.

It is worth noting that, even after clarifying that vaccines do not make people contagious (an issue on which Capua and Burioni are in agreement), there are still two points of factual contention between Capua and Burioni: on how many vaccines grant in fact sterilizing immunity (very few according to Capua, many for Burioni), and on whether anti-Covid vaccines prevent infection (Capua talks as if we knew they do not, whereas Burioni explicitly states that we do not know yet). Based on an interview released on November 24, 2020 on Axios ${ }^{4}$ by Tal Zaks, Chief Medical Officer of Moderna Inc. and thus at the forefront of the development of anti-Covid vaccines, Burioni's position seems to be the most accurate, given the evidence available at that time:

I think we need to be careful, as we get vaccinated, not to over-interpret the results. Our results show that this vaccine can prevent you from being sick, it can prevent you from being severely sick. They do not show that it prevents you from potentially carrying this virus transiently and infecting others. When we start the deployment of this vaccine, we will not have sufficient concrete data to prove that this vaccine reduces transmission. Do I believe that it reduces transmission? Absolutely yes, and I say this because of the science. But, absent proof, I think it is important that we do not change behaviours solely on the basis of vaccination.

While sharing Capua's admonishment against a "free for all" attitude once vaccination starts to be widespread, Zaks' statement makes it clear that in November 2020 there were not enough data to prove sterilizing immunity for anti-Covid vaccines, yet the medical evidence on vaccines in general justified the tentative expectation that they would prove effective also in curtailing transmission. Incidentally, recent evidence seems to vindicate such expectation, at least with respect to mRNA anti-Covid vaccines (Thompson et al., 2021).

Still, we are left with the other fundamental problem raised by Capua's public discussion of sterilizing immunity: if anti-Covid vaccines do not grant protection

\footnotetext{
${ }^{3}$ Source (in Italian, spread across two tweets): https://twitter.com/robertoburioni/status/133170702 1536661510.

${ }^{4}$ Source: https://www.youtube.com/watch?v=po7qt9BZz0s.
} 
against transmission, or if that protection is only partial, or if we do not know yet what to expect on that, then how can herd immunity be presented as the ultimate aim of vaccination? Contagion will not stop in the herd, no matter how many members get vaccinated, unless vaccines grant immunity from transmission: yet we still do not know whether they will, or to what extent. To make things worse, there are also other reasons to fear herd immunity may be a pipe dream for Covid-19 (Aschwanden, 2021): in addition to the unknown quantity of sterilizing immunity, vaccine rollout is uneven across different countries (and herd immunity can be effective only at a global scale, in our interconnected world), new variants of the virus change the herd immunity equation (since some vaccines may be less effective, or not effective at all, against certain variants), the duration of the immunity granted by vaccines is still uncertain, and, finally, vaccination change behaviours, typically making people less careful to avoid contagion-the very same worry that led Capua to speak up about sterilizing immunity, and prompted even one of the leading scientists developing a highly effective vaccine (Moderna) to suggest caution.

All considered, if herd immunity is supposed to be the carrot to get people vaccinated, it looks like a rotten one. Crucially, its faults are argumentative, not medical: there is nothing scientifically wrong with the concept of herd immunity, once properly understood; it is the poor use of it in the context of vaccine discourse that is to be blamed. Given the goal of persuading people to vaccinate as soon as possible against Covid-19, the herd immunity argument has two fatal flaws.

The first one is that it is likely to backfire, for all the reasons we just discussed: if herd immunity against Covid-19 turns out to be a myth, or if even the mere suspicion of it starts spreading in the general public (as it is already happening), then its value as a reason for vaccination will collapse, possibly producing a crisis of trust in vaccines in general. Selling people on a dream is always risky business, and doing so in relation to a pandemic is reckless.

The second problem is even more fundamental: promising herd immunity as our collective reward for mass vaccination is directly in conflict with another key aim of public authorities-namely, having people maintain safety measures and protective behaviours even after vaccination. The complex communicative gymnastic that medical experts like Capua and Zaks had to perform is a direct consequence of the untenable network of incompatible goals projected by a communication strategy determined to use herd immunity as the holy grail of vaccination. You cannot feed people conflicting messages, like "Take your vaccination shot, so that we may all soon live in a Covid-free world!" and "Don't go clubbing once vaccinated, you are still a leper in disguise!", without expecting them to get confused and start doubting the rationale of the vaccination campaign. The problem is not in the lack of understanding of the general public, nor in the occasionally defective communications issued by individual experts: it is in the poor argumentative choices made by the institutions in charge of dealing with the pandemic.

What is particularly striking in this case is that there is a potentially better reason to get people eager to vaccinate (a tastier carrot, if you like): the veridical promise of being protected from the symptoms of the infection, and in particular from its direst consequences, including death and permanent invalidity. Moreover, this line 
of argument can leverage both self-interested goals (self-protection from harm) and altruistic motives - namely, preventing hospitals from being overrun by severe cases of Covid-19. In fact, in the absence of specific medicines capable of targeting the illness, the most problematic feature of Covid-19 has always been the high rate of infected subjects requiring medical treatment in intensive care units, which in turn has often created unbearable strain on the healthcare systems of the most affected countries. By guaranteeing full protection from severe consequences of the infection, vaccination is the single most powerful tool at our disposal to avoid catastrophic breakdowns of healthcare facilities (which, incidentally, are critical for all severe pathologies, including those other than Covid-19): this, in turn, is the chief concern of the worldwide strategy against the pandemic.

Finally, promoting vaccination by framing it as a shield against harm (to ourselves and to our collective resources) is also perfectly compatible with the other key goal of institutional communication on vaccination, that is, ensuring that people remain cautious and observant of containment measures even after getting their shot. Contrary to what happens with the herd immunity gambit, here both getting vaccinated and endorsing other sanitary precautions share the same goal: protecting each of us from harm and avoiding overtaxing the healthcare system. This allows institutions to promote vaccination as aggressively as needed, without fear of equivocation and no need of convoluted ex post clarifications, like the ones that Capua and others were forced to attempt.

To summarize, let us compare the two main arguments available to promote vaccination. On the one hand, we have herd immunity, for which we currently have no sound evidence, while there are several reasons to suspect it may never be achieved, and that is also at odds with the concomitant goal of keeping people prudent in their behaviours. On the other hand, we have protection from harm, which is supported by (literally) millions of data, is virtually guaranteed, and plays well with the aim of avoiding untimely relaxation of other safety measures. The main thing that herd immunity has going for it is a rhetorical connotation: it is better at evoking pleasant fantasies of a happy return to the status quo of normal habits and crowded interactions, whereas protection from harm keeps reminding us that the fight is far from over-hence the collective need to get up our shields, i.e. vaccines, as quickly as possible. The allure of the positive spin characteristic of the herd immunity argument is easy to understand, especially for politicians eager to stop bombarding their constituents with negatively charged public messages. Yet this allure is at risk of being short-sighted: not only because the herd immunity argument is likely to backfire, once it becomes apparent nothing of the sort will be achieved any time soon; but also because reminding people that the fight is far from over is precisely what institutional communication on the pandemic should strive to achieve, while the herd immunity argument undermines that. ${ }^{5}$

\footnotetext{
${ }^{5}$ This second element is essential, because without it there might be good reasons to doubt the effectiveness of a communication campaign focused on protective goals: for instance, it may fail with all kinds of people who feel that they themselves are not at risk, and the altruistic side-benefit (reducing demand on hospital resources) may also disappear for those who are convinced they will
} 
Unfortunately, this argumentative blunder is not an isolated instance in institutional communication about the pandemic. Another similar failure, once again tied to poor argumentative design, is the recent debacle of vaccine communication in the EU. In addition to being initially quite slow in vaccine roll out, at least compared to other countries (e.g., US, UK, Israel, Chile), most European institutions and several national governments of member countries managed to baffle and confuse their citizens during the first half of 2021, in their bungled attempts at keeping them confident in anti-Covid vaccines. According to some commentators, the relationship between the EU and anti-Covid vaccines was flawed since the very beginning: Paul Krugman, winner of the 2008 Nobel Prize in Economics, recently wrote an op-ed for The New York Times, significantly entitled "Vaccines: a very European disaster", ${ }^{6}$ in which he argued that the EU priorities on vaccination were curiously skewed.

The common thread seems to be that European officials were not just risk averse, but averse to the wrong risks. They seemed deeply worried about the possibility that they might end up paying drug companies too much, or discover that they had laid out money for vaccines that either proved ineffective or turned out to have dangerous side effects. So they minimized these risks by delaying the procurement process, haggling over prices and refusing to grant liability waivers. They seemed far less worried about the risk that many Europeans might get sick or die because the vaccine rollout was too slow.

Subsequent events confirmed this European tendency to be penny-wise and poundfoolish in managing vaccine-related risks: after uncovering very few lethal cases of cerebral thrombosis in people vaccinated with AstraZeneca (about 30 cases out of several millions of doses administered), in March and April 2021 the use of this vaccine was suspended across most European countries, as well as in other parts of the world, pending further investigation by the competent authorities - in the case of the EU, the European Medicines Agency (EMA). In early April the EMA concluded its investigation, confirming that the benefits of the vaccine far outweigh its risks, yet suggesting the likelihood of a (very rare) causal link between vaccination with AstraZeneca and the reported fatalities.

As a consequence, amendments to the vaccine information sheet were mandated, and different levels of risk (all minuscule) were reported for various age groups: based on this information, most EU countries decided to restart administering this vaccine, yet limiting its use to people over 60 . Incidentally, this constituted a complete reversal of previous recommendations: up to that point, the AstraZeneca vaccine had been typically recommended only for people under 65 , due to lack of data on its effectiveness outside of this age cohort. ${ }^{7}$ In all this turmoil, the fact that AstraZeneca is by far the cheapest anti-Covid vaccine available in the EU (one dose costs about one

not get sick (Chevallier et al., 2021). However, this does not change the fact that herd immunity is not a serviceable argument to simultaneously promote mass vaccination and respect of other safety measures by vaccinated people.

${ }^{6}$ Source: https://www.nytimes.com/2021/03/18/opinion/coronavirus-vaccine-europe.html.

${ }^{7}$ The early reluctance to use the AstraZeneca vaccine with people over 65 was also tied to an article published on January 24, 2021, in the German newspaper Handelsblatt, claiming that the vaccine had only $8 \%$ efficacy in elderly people. These claims turned out to be completely unfounded soon after, but not before they were picked up and publicly endorsed on January 29, 2021, by the President 
tenth of a dose of Pfizer or Moderna) has been conspicuously downplayed, although the impact of paying ten times more to vaccinate a significant portion of the European population is unlikely to prove trivial.

It is also worth noticing that this PR disaster (Wise, 2021) happened in the context of an already strained relationship between the EU and the manufacturer, due to the latter failure to deliver in time most of the doses stipulated in its contract with the EU: a dispute that led the EU to launch a legal action against AstraZeneca for breach of contract on April 26, 2021. However, the manufacturers are not the only ones to blame for this argumentative blunder: regulatory agencies, like the EMA, consistently employed obscure and fear-inducing jargon to communicate on the issue ("a causal link is not proven, but is possible", "overall benefits outweigh dangers", "higher risks in certain age groups", just to mention a few), national European governments were overzealous in suspending administration of this vaccine and limiting its use to specific age groups, and the media were quick to pick up every rumors and magnify them a thousand fold-e.g., on March 12, 2021, La Repubblica, one of the main Italian newspapers, had a gigantic headline on its front page, reading "AstraZeneca, fear in Europe".

Regarding regulatory agencies, their main communicative shortcoming in this crisis was to stick too much to "science talk", without understanding how concepts like "uncertainty", "small probabilities", "benefit/risk ratio" plays out in the general public, and apparently also with policy makers (a well-known issue with risk communication; Hansson, 2009; Richards \& Den Hoed, 2018). As for policy makers, they were again stuck with inconsistent argumentative and practical commitments: besides the complete turnabout on the recommended age for vaccination with AstraZeneca, they were trying to simultaneously reassure people on the negligible risks associated with this vaccine, while at the same time discouraging its use for the vast majority of the population. It is a lot like saying "Look, this water is $100 \%$ potable, yet I wouldn't drink it if I were you...": people cannot be blamed for being hesitant to take the AstraZeneca vaccine, in the face of such conflicting messages from their governments and medical institutions. Not to mention the idea of trying to sell the vaccine with the benefit/risk mantra, instead of emphasizing the much higher risks that we are all already facing because of the virus, and how vaccines (including AstraZeneca) drastically reduce those risks.

Inevitably, the first to pay the price of this bungled argumentative strategy are the manufacturers of the vaccine: in spite of some desperate last-ditch attempts at redeeming their reputation, e.g. by changing the name of the vaccine itself (it goes now under the moniker "Vaxzevria"), what was once a company poised to be one of the big winners in vaccine development and marketing, due to the very competitive price of their product, is now on the brink of disaster, with orders being rescinded, use of the vaccine being limited to specific age cohorts in several countries and stopped altogether in others (e.g., Denmark), and the EU on the legal warpath. However, AstraZeneca will not be the only one to suffer from this PR nightmare:

of France, Emmanuel Macron, who declared the AstraZeneca vaccine to be "quasi-ineffective" in over $65 \mathrm{~s}$. 
their vaccine, because of its low price and ease of transportation and storage, was (and still is, in principle) a key part of the vaccination strategy proposed by the World Health Organization (WHO); moreover, as mentioned, having to pay ten times more to vaccinate millions of people will have huge economic consequences, which in turn will aggravate the already severe societal impact of the pandemic; finally, this collective argumentative fiasco will likely fuel vaccine hesitancy for years to come, at a time when governments are in desperate need of getting as many people as possible to vaccinate, as quickly as possible.

From an argumentative standpoint, these incidents teach us that awkward and problematic communicative performances by individual actors need to be understood in the broader context of institutional communication and its underlying media ecology: not because individual actors are necessarily speaking on behalf of institutions (Capua was not, for instance), but because their thematic agenda and their argumentative moves are constrained by the communicative strategies that currently shape public discourse on that topic (Aakhus, 2007). With respect to the pandemic, and to vaccination in particular, some of those strategies turned out to be sub-optimal, to say the least. This, in turn, suggests a twofold dimension of relevance for argumentation theory, in supporting rational and effective public discourse on healthrelated issues: not only as a tool to refine message crafting in relation to specific communicative acts, but also (and perhaps mostly) as a frame of reference to design better argumentation strategies to convey the key points of broader communication campaigns. As a case in point, input from argumentation scholars could have greatly helped the EU to leverage better reasons and focus on different issues, in its efforts of promoting mass vaccination in member states.

\subsection{Conclusions: How to Save the World with Arguments}

Although the title of this section is a bit of a stretch, the importance of proper argumentative design for achieving effective communication, rational debate, and sensible collective behaviours is not to be underestimated, as the case study discussed in this chapter aimed to clarify. A sound theoretical understanding of argumentative structures and their foreseeable interpretation by the intended audience is crucial to ensure both better message crafting on specific issues, and effective orchestration of large-scale campaigns on complex topics. However, the (mostly negative) examples offered by the recent pandemic communication also illustrate another interesting fact: in order to be relevant for public discourse, argumentation theory needs to get out of its comfort zone and explore partially new grounds.

To begin with, argumentation scholarship may need to take a more decisive empirical turn to stay relevant in this arena. Perceptive readers have certainly realized by now that much of the previous analysis of argumentative mistakes in pandemic communication was based on hindsight, which is a nice commodity for the analyst, but unfortunately it is never available to those charged with managing public discourse in real life. The notion of argumentative strategy needs to take this 
into serious account: we can learn a lot by carefully reflecting on how different arguments may manage our multiple goals and what kinds of disagreement spaces they might open; yet this is only part of the story, since people continually surprise us in how they respond to what seem to be, on paper, really strong (or really weak) arguments. Incidentally, this is something well-known in health communication, where a mature technology of campaign design has emerged, anchored in persuasion theory, aimed at argument/message production, but centred on extensive testing of even the most plausible campaign ideas against how they will actually be received by audiences (Noar, 2006). Argumentation scholars should build on these best practices, keeping in mind both the problems raised by the new media ecology (in which orchestrating any coherent communication campaign is a formidable challenge) and the unique advantages offered by argumentation theories to this kind of empirical testing: most notably, a sophisticated framework to better appreciate not only what messages work, but also why they work, and what kind of force (logical, dialectical, rhetorical) is most likely responsible for their success.

However, treading relatively new ground will require argumentation scholars not only to increase their familiarity with empirical testing, but also to partially reconsider their theoretical framework. Indeed, none of the argumentative insights discussed in this chapter came from run of the mill applications of mainstream theoretical tools: for instance, establishing what argument schemes were used in communicating the pandemic was not one of our concerns, nor were we particularly interested in keeping track of the dialogical commitments of different parties involved in the debate, or in assessing what types of strategic maneuvering they might have employed in their communicative endeavors. In contrast, the main preoccupation was to investigate the factors responsible for making a certain message or a broad communication strategy effective or ineffective in promoting the desired behaviours, rather than taking as our gold standard some ideal of argumentative rationality. Clearly, sometimes effectiveness and rationality go hand in hand, typically because an argument derives part of its effectiveness, or lack thereof, from its underlying rationality: we saw a negative example of that in the previous section, where the conflicting commitments entailed by the herd immunity argument were suggested as its main communicative defect, and a severe risk to its effectiveness.

Yet a change of attitude may still be in order: while the traditional toolbox of argumentation theory remains very relevant for our purposes, those tools should be used to answer questions that really matter to the relevant stakeholders of public discourse, instead of limiting their application to some detached analysis of dialogical interactions, which unfortunately tend to have little or no impact in solving the issues under discussion. Today, in the face of a global pandemic, it is time for argumentation scholars to get in the trenches with scientists, policy makers, and media experts, and do their share of dirty work to get us out of this mess. Now is a time for intervention, not for analysis: or, more accurately, it is a time when every analysis must convey usable insight on how to intervene to make things better. There is a proud tradition of doing just that in the argumentation community, and many prominent argumentation scholars have demonstrated by example that such active advocacy is both possible and fruitful: for instance, Christian Kock's public outreach as a debate 
commentator in Denmark, David Hitchcock's work with the nursing community on critical thinking, the Deweyian-inspired tradition of public debates/discussions in the US (for an historical review, see Keith, 2007), and of course the very same APPLY network responsible for organizing this volume, which has adopted this kind of "prescriptive" work as one of its aims. The invitation here is thus to expand this line of work, and to consider it as central, rather than ancillary, to the collective enterprise of argumentation theories.

An interesting corollary of this change of attitude is the following, sobering reminder: for the argumentative structure and content of a message to matter, that message needs first to be heard. In this day and age, this means tackling the issue of virality - not as an enemy to fight or a cancer to eradicate, but rather as a tool to exploit. So far, argumentation theorists have focused almost exclusively on negative viral contents, first and foremost on fake news: either to refine the definition of the phenomenon (Gelfert, 2018), to articulate how it has subverted normal standards of argumentative reasonableness (Neville-Shepard, 2019), to document how it feeds on lack of analytic reasoning (Pennycook \& Rand, 2019), to suggest argument-inspired technologies to help dealing with it (Visser et al., 2020), to understand how deviant argumentative behaviours, e.g. trolling, shed light on how digital technologies change argumentation itself (Cohen, 2017), or to demonstrate how the very notion of disinformation can be used as a fallacious rhetorical device, e.g. when Donald Trump hollers "fake news!" at the top of his lungs to quickly silence dissenting voices (Zompetti, 2019). All these contributions are valuable, but there is no reason for argumentation theorists to confine their study of virality to disinformation: moreover, it is crucial to emphasize that what makes a content viral is not tied to its epistemic quality - neither positively nor negatively. Accurate news and blatant disinformation can become equally viral online (Cinelli et al., 2020), so we need to start harnessing the power of virality to ensure that good arguments and reliable data reach the general public faster and more widely than fallacious messages and fake news. In other words, virality is the much needed grease to make the argumentation engine run smoothly.

This brings us to the elephant in the room: the role of social media in the argumentative processes we have discussed so far. Current evidence does not support the idea that social media directly change the argumentative quality of public debate: however, they do act as powerful amplifiers of whatever message is put forward in public, both quantitatively (access is granted to many more people) and temporally (access persists for a much longer time), and they give voice to a much more diverse variety of sources. While it is patently false that anybody has the same degree of visibility on social media, it is certainly true that any centralized control of public discourse has become more difficult to achieve, especially for traditional players such as governments and official media. Incidentally, this development is not necessarily to be lamented; at the very least, it brings with it both advantages (e.g., greater transparency and more plurality) and dangers (e.g., too much noise, a shift of power from public governments to private companies, a climate of eternal campaigning in political communication). However, argumentation scholars have no reason to be "for" or "against" social media per se; instead, they need to study how their amplifying function raises the stake for public messages, especially when uttered by a 
credible or authoritative source. The previous analysis provides ample evidence of that: both individual messages and institutional campaigns on anti-Covid vaccines own a significant part of their impact to the secondary circulation of these claims on social media. As soon as a communicative act goes viral, its relevance is magnified a thousand fold: hence, we need to take seriously the task of making sure only appropriate arguments become viral.

A right step in this direction, and a fitting way of concluding this brief contribution on a cheerful note, is the "humor over rumor" strategy employed by the Taiwanese government to deal with online disinformation. The first Digital Minister of Taiwan and former civic hacktivist, Audrey Tang, is the mastermind behind this innovative approach to institutional communication, which played a significant role in making Taiwan by far the most successful country in the world in dealing with the Covid-19 pandemic: as of early May 2021, the country has reported only about 1300 cases and 12 deaths since the onset of the crisis, without ever imposing a national lockdown and in spite of its relative closeness to China, ${ }^{8}$ the original epicenter of the contagion. Part of this outstanding success is tied to their ability of maintaining an open line of communication with the general public and their highly effective tactics in dealing with problematic instances of disinformation.

As a case in point, in early 2020 Taiwan, like many other countries, experienced a collective frenzy to stockpile toilet paper, fueled by the rumor that the raw materials and production lines used for sanitary masks were the same normally used for toilet paper, hence a massive shortcoming of the latter was believed to be imminent. The Taiwanese administration promptly applied their humor over rumor strategy, which consists in using humorous memes to spread quickly and widely the correct information about a controversial issue: since the jury is still out on whether humor-based or logic-based correction of fake news is more effective (according to extant evidence, it depends on context; Vraga et al., 2019), the Taiwanese pragmatic approach is to employ both in synergy, instead of considering them as alternative options.

In the case of the toilet paper panic, they issued a cartoon of the Prime Minister, Su Tseng-chang, standing in front of a table reporting all the correct information on how sanitary masks are produced (nothing to do with toilet paper, by the way...): the image was an animated GIF, so that the Premier could be seen vigorously shaking his bottom (or, as they say today, "twerking") under the punchline of the meme, "Remember: we all have only one butt!". As expected, the GIF went viral in a matter of hours, soon becoming much more visible than the rumor that it was designed to counteract: after having a laugh about their twerking Prime Minister, Taiwanese were able to get their facts straight about sanitary mask production, so the toilet paper stockpiling stopped almost overnight. This kind of success vindicates yet another motto of the Taiwanese government strategy for communicating with their citizens: "fast, fair, and fun".

What is remarkable is not only the systematic use of virality to convey positive messages, but also the decision to do so professionally: Audrey Tang is fond of saying

\footnotetext{
${ }^{8}$ In fact, the official position of the Chinese government is that Taiwan is part of the People's Republic of China, albeit the Taiwanese people beg to differ.
} 
that one of her greatest successes as Taiwan's first Digital Minister was to persuade the rest of the Government to employ hundreds of comedians to help curating their communication, so that the humor employed to fight rumor was, in fact, humorous, i.e. funny and therefore effective.

Argumentation theory should pay heed to this brilliant idea. Jokes are not typically arguments, although they can function in similar ways (Conley, 2004), play a key role in managing dissensus (Rose, 2007) and in articulating controversial political topics under the guise of lightly remarks (Waisanen, 2015). But the beauty of the humor over rumor strategy is that the joke plays an independent role, with respect to the content. Being humorous is our ticket to virality, which in turn allows our message to be heard loud and clear (and with an open mind) by as many people as possible. Sure, there are boundaries on the kind of humor that is appropriate for such purposes: for instance, great care must be taken to ensure that the joke does not offend anyone. This is exactly the reason why the Taiwanese government wisely chose to employ professional comedians, instead of asking public servants to improvise. As a result, the professional touch is palpable in the quality of their messages, since the devil (notoriously a great humorist) is in the detail: in the example just discussed, the one person twerking in front of the masses is not a random citizen, but rather the Prime Minister, and the message reads "we all have only one butt", rather than "you all have only one butt".

Similar minutiae mark the difference between a successful viral institutional campaign and a PR disaster: hence, we should all consider starting to channel our inner comedian, if we want to make sure our judicious and well-formed arguments gain the traction they need to really make a difference in public debate. More seriously, we all need to realize that virality is a serious challenge for argumentation theory, not an annoyance to bypass. This does not mean that argumentation scholars should strive to become professional comedians: it does mean, however, that argumentation theory will need to integrate with other areas of expertise, to be able to realize its societal impact. Making sure good arguments are heard, or read on a social media feed, is not something we can shrug off as "someone else's business": it is our business, and we need to take care of it by joining forces more often with virality experts, communication design scholars, and persuasion researchers.

Acknowledgements This publication is based upon work from COST Action CA-17132 European Network for Argumentation and Public Policy Analysis (http://publicpolicyargument.eu), supported by COST (European Cooperation in Science and Technology).

\section{References}

Aakhus, M. (2007). Communication as design. Communication Monographs, 74(1), 112-117.

Altheide, D., \& Snow, R. (1979). Media logic. SAGE Publications.

Aschwanden, C. (2021). Five reasons why COVID herd immunity is probably impossible. Nature, 591(7851), 520-522. 
Carr, N. (2008). Is Google making us stupid? What the Internet is doing to our brains. The Atlantic Monthly (Jul/Aug 2008).

Carr, N. (2020). The shallows: What the Internet is doing to our brains. WW Norton \& Company. Chevallier, C., Hacquin, A.-S., \& Mercier, H. (2021). COVID-19 vaccine hesitancy: Shortening the last mile. Trends in Cognitive Sciences, 25(5), 331-333.

Cinelli, M., Quattrociocchi, W., Galeazzi, A., Valensise, C. M., Brugnoli, E., Schmidt, A. L., Zola, P., Zollo, F., \& Scala, A. (2020). The Covid-19 social media infodemic. Scientific Reports, 10(1), $1-10$.

Cohen, D. H. (2017). The virtuous troll: Argumentative virtues in the age of (technologically enhanced) argumentative pluralism. Philosophy \& Technology, 30(2), 179-189.

Conley, T. (2004). What jokes can tell us about arguments. In W. Jost \& W. Olmsted (Eds.), A companion to rhetoric and rhetorical criticism (pp. 266-277). Blackwell.

Dertouzos, M. (1997). What will be: How the new world of information will change our lives. Harper Edge.

Floridi, L. (2014). The fourth revolution. How the infosphere is reshaping human reality. Oxford University Press.

Gelfert, A. (2018). Fake news: a definition. Informal Logic, 38(1), 84-117.

Hansson, S. O. (2009). From the casino to the jungle. Synthese, 168(3), 423-432.

Howell, L. (Ed.). (2013). Global risks 2013 (8th ed.). World Economic Forum.

Keith, W. (2007). Democracy as discussion: Civic education and the American forum movement. Lexington Books.

Krugman, P. (2021). Vaccines: A very European disaster. The New York Times, 18 March 2021.

Lanier, J. (2018). Ten arguments for deleting your social media accounts right now. Random House.

Negroponte, N. (1995). Being digital. Knopf.

Neville-Shepard, R. (2019). Post-presumption argumentation and the post-truth world: On the conspiracy rhetoric of Donald Trump. Argumentation and Advocacy, 55(3), 175-193.

Noar, S. (2006). A 10-year retrospective of research in health mass media campaigns: Where do we go from here? Journal of Health Communication, 11(1), 21-42.

Paglieri, F. (2017). A plea for ecological argument technologies. Philosophy \& Technology, 30(2), 209-238.

Pennycook, G., \& Rand, D. G. (2019). Lazy, not biased: Susceptibility to partisan fake news is better explained by lack of reasoning than by motivated reasoning. Cognition, 188, 39-50.

Richards, G. W., \& Den Hoed, R. C. (2018). Seven strategies of climate change science communication for policy change: Combining academic theory with practical evidence from science-policy partnerships in Canada. In Handbook of Climate Change Communication: Vol. 2 (pp. 147-160). Springer.

Rose, P. (2007). Dissensus and the rhetorical function of humour. In H.V. Hansen (Ed.), Dissensus and the search for common ground (CD-ROM, pp. 1-9). OSSA.

Shapiro, A. (1999). The control revolution. Century Foundation.

Sunstein, C. (2001) Republic.com. Princeton University Press.

Surowiecki, J. (2004). The wisdom of crowds: Why the many are smarter than the few and how collective wisdom shapes business, economies, societies, and nations. Doubleday.

Thompson, M., Burgess, J., Naleway, A., Tyner, H., Yoon, S., Meece, J., Olsho, L., Caben-Martinez, A., Fowlkes, A., Lutrick, K., Kuntz, J., Dunnigan, K., Odean, M., Hegmann, K., Stefanski. E., Edwards, L., Schaefer-Solle, N., Grant, L., Fllingson, K., Groom, H., ... Gaglani, M. (2021). Interim estimates of vaccine effectiveness of BNT162b2 and mRNA-1273 COVID-19 vaccines in preventing SARS-CoV-2 infection among health care personnel, first responders, and other essential and frontline workers-Eight U.S. locations, December 2020-March 2021. Morbidity and Mortality Weekly Report (MMWR) of the CDC, vol. 70 (pp. 495-500).

Turkle, S. (2011). Alone together: Why we expect more from technology and less from each other. Basic Books.

van Dijck, J., \& Poell, T. (2013). Understanding social media logic. Media and Communication, 1(1). https://doi.org/10.12924/mac2013.01010002 
Visser, J., Lawrence, J., \& Reed, C. (2020). Reason-checking fake news. Communications of the ACM, 63(11), 38-40.

Vosoughi, S., Roy, D., \& Aral, S. (2018). The spread of true and false news online. Science, 359(6380), 1146-1151.

Vraga, E. K., Kim, S. C., \& Cook, J. (2019). Testing logic-based and humor-based corrections for science, health, and political misinformation on social media. Journal of Broadcasting \& Electronic Media, 63(3), 393-414.

Waisanen, D. (2015). Comedian-in-Chief: Presidential jokes as enthymematic crisis rhetoric. Presidential Studies Quarterly, 45(2), 335-360.

Wise, J. (2021). Covid-19: How AstraZeneca lost the vaccine PR war. The British Medical Journal, $373,921$.

Zompetti, J. P. (2019). The fallacy of fake news: Exploring the commonsensical argument appeals of fake news rhetoric through a Gramscian lens. Journal of Contemporary Rhetoric, 9(3/4), $139-159$.

Open Access This chapter is licensed under the terms of the Creative Commons Attribution 4.0 International License (http://creativecommons.org/licenses/by/4.0/), which permits use, sharing, adaptation, distribution and reproduction in any medium or format, as long as you give appropriate credit to the original author(s) and the source, provide a link to the Creative Commons license and indicate if changes were made.

The images or other third party material in this chapter are included in the chapter's Creative Commons license, unless indicated otherwise in a credit line to the material. If material is not included in the chapter's Creative Commons license and your intended use is not permitted by statutory regulation or exceeds the permitted use, you will need to obtain permission directly from the copyright holder.

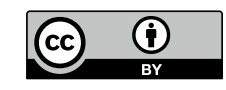

